\title{
A Rare Case of Frontal Lobe Abscess from Orbital Roof Blowout Fracture
}

\author{
AF Alkadhimi ${ }^{1 *}$, M Chung ${ }^{2}$ and AJ Sidebottom ${ }^{3}$ \\ ${ }^{1}$ Department of DCT2 Orthodontics and Oral and Maxillofacial Surgery, Queen's Medical Centre \& University of Nottingham NHS Trust, UK \\ ${ }^{2}$ Department of DCT1 Oral and Maxillofacial Surgery, Queen's Medical Centre \& University of Nottingham NHS Trust, UK \\ ${ }^{3}$ Consultant Oral and Maxillofacial Surgeon, Nottingham University Hospitals NHS Trust, UK
}

Submission: July 09, 2018; Published: August 24, 2018

*Corresponding author: Aslam Alkadhimi, Division of Oral and Maxillofacial Surgery and Orthodontics, Queen's Medical Centre, Derby Rd, NG7 2UH, UK, Tel: +447490193715; Email: aslam.alkadhimi@nhs.net

Abstract

Orbital roof fractures are rare. These fractures are usually associated with high velocity impact and polytrauma, and if misdiagnosed, can have serious complications. This case demonstrates that orbital roof fractures can be easily missed from plain film radiographs and that clinical history and signs are of paramount importance in assessing these cases. This case also emphasizes the importance of multidisciplinary approach in trauma care.

Keywords: Frontal lobe abscess; Orbital roof fracture; Polytrauma

\section{Introduction}

Orbital roof fractures are usually associated with high impact trauma, accounting for approximately $1-9 \%$ of all maxillofacial fractures [1]. These fractures are mostly associated with other injuries in frontobasal trauma [2], although infants have a relatively high incidence of orbital roof fractures because of absent pneumatisation of the frontal sinus [3]. These fractures rarely present in isolation and can be associated with significant complications involving the eye, orbit, extraocular muscles, and brain.

Typically, the mechanism of injury for orbital roof fractures is high-velocity/impact trauma such as motor vehicle/bike accidents, and assaults. Facial lacerations as a result of the trauma may be presentalong with periorbital oedema, ecchymosis, ocular discomfort and epiphora. If there is involvement of the superior oblique or rectus muscles, the patient may have limitation of vertical or inward gaze or diplopia. Altered sensation in the distribution of the supraorbital and supratrochlear nerves may be present, and if the fracture is displaced, ex- or enophthalmos, hyper- or hypoglobus, or proptosis may result. Timely diagnosis of orbital roof fractures is imperative to prevent potential ophthalmological, neurological and cosmetic morbidity. This is confirmed with radiology, preferably computed tomography (CT).

\section{Case Report}

A medically fit 34-year-old woman initially presented to the Emergency department following a fall from her bike in which she hit the left orbit with handlebar. Plain film radiographs (OM $10 \mathrm{o}$ and 30o) showed no evidence of any facial fractures (Figure $1 \& 2$ ). Clinically, she had diplopia on lateral gaze associated with left eye and a small laceration on the upper eyelid which was glued by A \& E. A 2-week review was planned by ophthalmology.

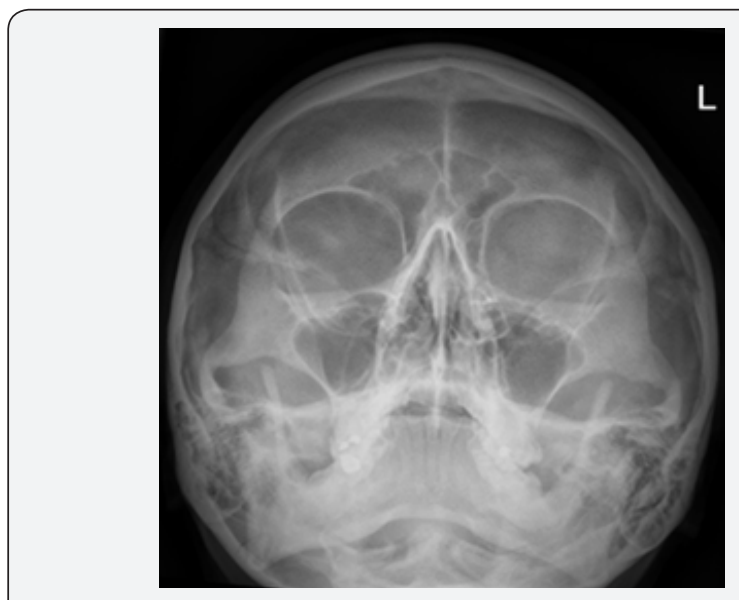

Figure 1: $\mathrm{OM} 10^{\circ}$ view with no evidence of bony fractures. 


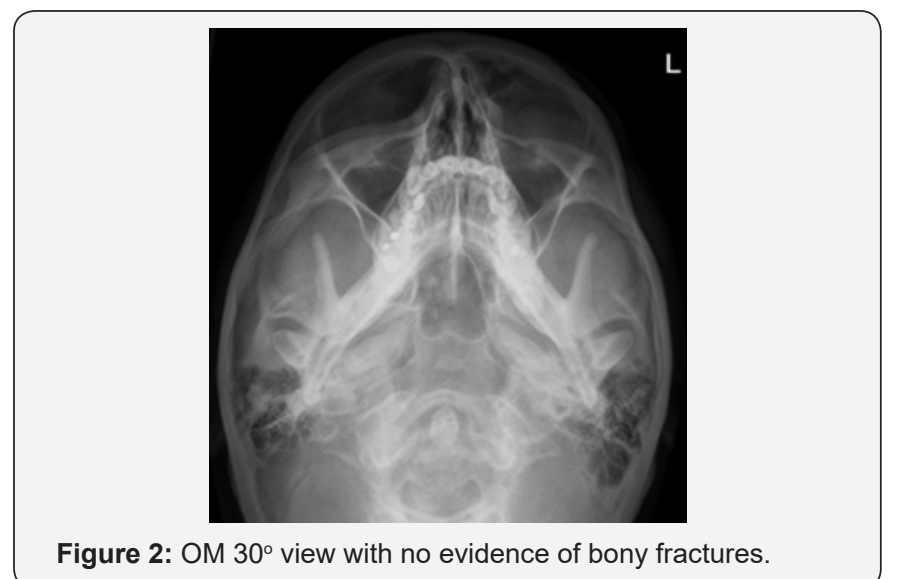

She attended the eye casualty department 7 days after the initial trauma complaining of restriction of movement. Examination revealed restricted ocular motility and diplopia on all direction of gaze left eye particularly downwards.

A CT scan revealed a blowout fracture through the superomedial left orbital cavity with displaced fragments projected $2 \mathrm{~cm}$ into the left frontal lobe and she was referred to Maxillofacial Surgery (Figure 3). Following discussion with neurosurgery an MRI was arranged to exclude brain abscess. This Figure 4 showed abscess formation around the left frontal lobe. The patient had urgent bi-frontal craniotomy and drainage of the abscess. Due to risk of infection of the bone or alloplastic graft, no roof repair was performed. She remains well at 6 months follow up with no signs of pulsatile exophthalmos or enophthalmos.

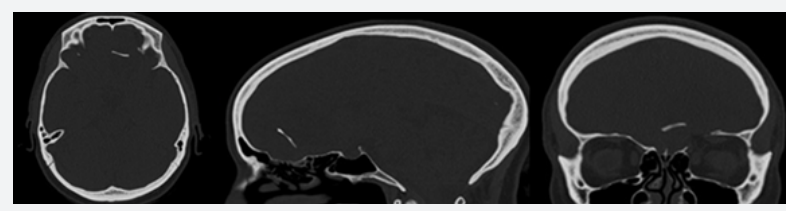

Figure 3: Axial, sagittal and coronal CT slices showing the displaced superiomedial fragment of the left orbital roof.

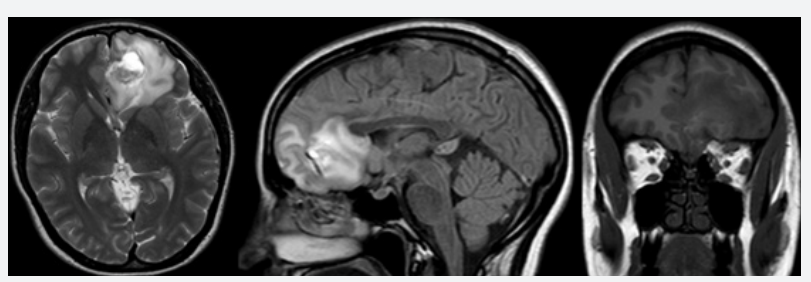

Figure 4: Axial, sagittal and coronal MRI slices showing the left frontal lobe abscess as a result of the displaced fragment of orbital roof.

\section{Discussion}

Orbital roof fractures have been reported to account for between $1 \%$ and $9 \%$ of facial bone fractures [1,4]. Isolated orbital roof fractures are rare. The majority are associated with other forms of neurologic injury. They are often the result of high-energy impacts, such as motor vehicle accidents or falls [5]. Non-displaced or minimally displaced orbital roof fractures generally do not require surgical intervention and are managed conservatively [3]. However, displaced orbital roof fractures may be associated with significant neurologic, ophthalmologic, and aesthetic morbidities, such as blindness, globe rupture, eye immobility, altered sensation of the supraorbital and supratrochlear nerves, CSF leakage, intracranial injury, enophthalmos, exophthalmos, ectropion, entropion, infection, diplopia, restricted extraocular movements, blepharoptosis, orbital volume discrepancy, and those associated with the presence of foreign bodies [1]. Surgical approaches to the orbital roof present a risk of intracranial infection due to the proximity of the frontal sinuses, concomitant dura tears, and CSF leaks associated with pneumocephalus [6]. Surgical approaches require multidisciplinary strategies involving maxillofacial surgeons, neurosurgeons, and ophthalmologists. Early reconstruction, within 10 days of trauma, by stabilizing the midfacial fractures facilitates anatomical reconstruction because bone margins remain intact and helps to reduce the need for secondary operations and reduce the risk of infection [7].

Early recognition and treatment of orbital roof fractures can reduce the incidence of intracranial and ocular complications. CT scan plays a major role in the assessment of acute orbital trauma. This case demonstrates how plain film radiographs alone have a low sensitivity in diagnosing orbital roof fractures. Careful clinical assessment and early consideration for CT scans are important.

\section{References}

1. Haug RH, Van Sickels JE, Jenkins WS (2002) Demographics and treatment options for orbital roof fractures. Oral Surg Oral Med Oral Pathol Oral Radiol Endod 93(3): 238-246.

2. Manson PN, Stanwix MG, Yaremchuk MJ, Nam AJ, Hui-Chou H, et al. (2009) Frontobasal fractures: anatomical classification and clinical significance. Plast Reconstr Surg 124(6): 2096-2106.

3. Fulcher TP, Sullivan TJ (2003) Orbital roof fractures: management of ophthalmic complications. Ophthalmic Plast Reconstr Surg 19(5): 359363.

4. Rinna C, Rocchi G, Ventucci E, Pagnoni M, Iannetti G (2009) Bilateral orbital rooffracture. J Craniofac Surg 20(3): 737-742.

5. Greenwald MJ, Boston D, Pensler JM, Radkowski MA (1989) Orbital roof fractures in childhood. Ophthalmology 96(4): 491-496.

6. Messinger A, Radkowski MA, Greenwald MJ, Pensler JM (1989) Orbital roof fractures in the pediatric population. Plast Reconstr Surg 84: 213216.

7. Converse JM, Hogan VM (1970) Open-sky approach for reduction of naso-orbital fractures: case report. Plast Reconstr Surg 46(4): 396-398. 

(C) (i) This work is licensed under Creative
Your next submission with Juniper Publishers will reach you the below assets

- Quality Editorial service

- Swift Peer Review

- Reprints availability

- E-prints Service

- Manuscript Podcast for convenient understanding

- Global attainment for your research

- Manuscript accessibility in different formats

( Pdf, E-pub, Full Text, Audio)

- Unceasing customer service

Track the below URL for one-step submission https://juniperpublishers.com/online-submission.php 